\title{
Meteorite Fall at Sadiya, India: A Raman Spectroscopic Classification
}

Bhaskar J Saikia ${ }^{1 *}$, Parthasarathy $\mathbf{G}^{2}$, Borah RR $^{3}$, Borthakur $\mathbf{R}^{3}$ and Sarmah AJD ${ }^{4}$

${ }^{1}$ Department of Physics, Anandaram Dhekial Phookan College, Nagaon, India

${ }^{2}$ National Geophysical Research Institute (CSIR-NGRI), Hyderabad, India

${ }^{3}$ Department of Physics, Nowgong College, Nagaon, India

${ }^{4}$ Department of Physics, Assam Downtown University, Guwahati, India

\begin{abstract}
This report demonstrates compositional, spectroscopic and mineralogical analysis of a new meteorite that fell at Natun Balijan village of Sunpura, Sadiya, India on June 5, 2017. The olivine and pyroxene composition $\left(\mathrm{Fa}_{28.97}\right.$; $\mathrm{Fo}_{71.03} ; \mathrm{Fs}_{24.47} ; \mathrm{En}_{74.03}$ and $\mathrm{Wo}_{1.5}$ ) of the meteorite are determined. The measured Raman band positions are consistent with chemical composition for olivine and pyroxene. The compositional and spectroscopic analysis of the Sadiya meteorite sample show that the meteorite belongs to LL-5 type chondrite.
\end{abstract}

Keywords: Meteorite; Sadiya; Raman spectroscopy

\section{Introduction}

Meteorites are the only physical materials available on the Earth that allow direct study of the original dust from which the Solar System formed. The standard method for identifying meteorites is to compare the chemical composition of the sample with that of the meteoritic rock previously studied [1]. Classification of ordinary chondrite meteorites generally implies determining the chemical group by the composition in endmembers of olivine and pyroxene, and identifying the petrologic group by microstructural features [2]. Raman spectroscopy can be used as an alternative technique to determine the endmember content of olivine and pyroxene in ordinary chondrites. The distribution of Fe and $\mathrm{Mg}$ in olivine and pyroxene structures is reflected by the peak position in the Raman spectra because of the different size of the two ions, therefore providing a correlation between the obtained spectrum and the chemical composition [2].

We report here a recent meteorite fall that occurred on June 5, 2017 (04:30 pm IST) in Natun Balijan village of Sunpura, Sadiya (2750'09"N; $\left.95^{\circ} 51^{\prime} 34^{\prime \prime} \mathrm{E}\right)$. Generally, meteorites are named from their place of find or fall. Therefore, the recent fall meteorite studied here is named as Sadiya. According to the eye witness, a single stone was fallen in paddy field with a roaring sound and it formed an impact pet about $3.5 \mathrm{ft}$ depth. The stone was fully covered with fusion crust and had well rounded edges and well developed regmaglypts on its surface (Figure 1). The weight of the meteorite was $3 \mathrm{~kg}$ and had specific gravity of about $3.4 \mathrm{~g} / \mathrm{cm}^{3}$, typical of stony meteorites. A small part of the sample was taken for analysis and the main stone under custody of the district administration. The Sadiya meteorite fall represent the fifth 'observed fall' in North East India and it is the seventh meteorite of this region since 1846 [3]. This report demonstrates usefulness of Raman spectroscopic technique for classification of meteorite. The Raman spectroscopy could be used to analyze individual mineral grains in a completely non-destructive way, and it offers some unique capabilities as an analytical method in the study of the extent of the shock metamorphism in a chondrite, prior to the microscopical study [4]. Our preliminary compositional, spectroscopic and mineralogical analysis of the Sadiya meteorite sample show that the meteorite belongs to LL-5 type chondrite.

\section{Methodology}

Studies on bulk and mineralogical composition of meteorites provide very important constraint for testing theories of Solar System formation. As meteorites retain a record of the elements, and mineral phases that existed in the system's accretionary stages. Microanalysis was performed using scanning electron microscopy (LEO 1430vp SEM) coupled with Oxford INCA energy dispersive X-ray spectrometer at accelerating voltage $20 \mathrm{kV}$ and working distance $10 \mathrm{~mm}$. A part of the sample was ground in an agate mortar and used for bulk chemical analysis of major and trace elements. The Raman spectra were collected on bulk powdered meteorite samples using an Ar ion laser laser with a power of $\sim 5 \mathrm{~mW}$, which used an excitation source having wavelength $488 \mathrm{~nm}$ coupled with a Jobin-Yvon Horiba LabRam-HR Micro-Raman spectrometer equipped with an Olympus microscope with 10X, 50X and 100X objectives, using the method described elsewhere $[5,6]$.

\section{Result and Discussion}

The electron microscopic study of the meteorite sample reveals olivine, pyroxene and triolite as major minerals (Figure 2). All unweathered ordinary chondrites show these four iron-bearing minerals. Therefore, the presence of these minerals in Sadiya meteorite confirms that the meteorite under consideration is an LL-type ordinary chondrite

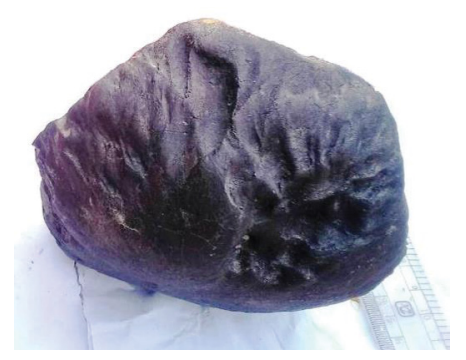

Figure 1: Photograph of Sadiya meteorite.

*Corresponding author: Bhaskar J Saikia, Department of Physics, Anandaram Dhekial Phookan College, Nagaon, India, Tel: +919678214200; E-mail: vaskaradp@gmail.com

Received August 11, 2017; Accepted September 18, 2017; Published September 20, 2017

Citation: Saikia BJ, Parthasarathy G, Borah RR, Borthakur R, Sarmah AJD (2017) Meteorite Fall at Sadiya, India: A Raman Spectroscopic Classification. J Astrophys Aerospace Technol 5: 149. doi:10.4172/2329-6542.1000149

Copyright: @ 2017 Saikia BJ, et al. This is an open-access article distributed under the terms of the Creative Commons Attribution License, which permits unrestricted use, distribution, and reproduction in any medium, provided the original author and source are credited. 

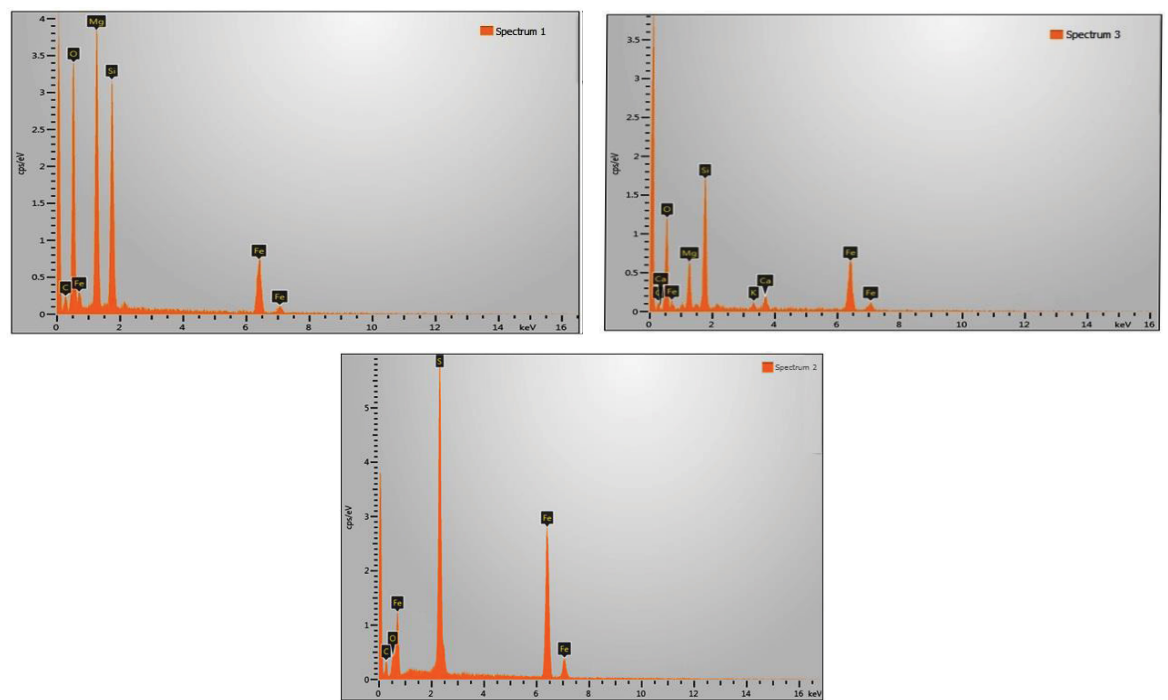

Figure 2: EDS spectra of minerals (Spectrum 1: Olivine; Spectrum 2: Pyroxene and Spectrum 3: Trolite of Sadiya meteorite.

\begin{tabular}{|c|c|c|c|c|c|}
\hline Elements (wt\%) & H & $\mathbf{L}$ & LL & $\mathrm{Cl}$ & Sadiya \\
\hline $\mathrm{Si}$ & 16.9 & 18.5 & 18.9 & 10.5 & 18.4 \\
\hline $\mathrm{Ti}$ & 0.06 & 0.063 & 0.062 & 0.042 & 0.23 \\
\hline $\mathrm{Al}$ & 1.13 & 1.22 & 1.19 & 0.86 & 1.46 \\
\hline $\mathrm{Cr}$ & 0.366 & 0.388 & 0.374 & 0.265 & 0.1 \\
\hline $\mathrm{Fe}$ & 27.5 & 21.5 & 18.5 & 18.2 & 18.04 \\
\hline $\mathrm{Mn}$ & 0.232 & 0.257 & 0.262 & 0.19 & 0.45 \\
\hline $\mathrm{Mg}$ & 14 & 14.9 & 15.3 & 9.7 & 15.11 \\
\hline $\mathrm{Ca}$ & 1.25 & 1.31 & 1.3 & 0.92 & 1.85 \\
\hline $\mathrm{Na}$ & 0.64 & 0.7 & 0.7 & 0.49 & 0.83 \\
\hline $\mathrm{K}$ & 0.078 & 0.083 & 0.079 & 0.056 & 0.68 \\
\hline$P$ & 0.108 & 0.095 & 0.085 & 0.102 & nd \\
\hline $\mathrm{Ni}$ & 1.6 & 1.2 & 1.02 & 1.07 & 0.64 \\
\hline Co & 0.081 & 0.059 & 0.049 & 0.051 & nd \\
\hline $\mathrm{S}$ & 2 & 2.2 & 2.3 & 5.9 & 0.29 \\
\hline Atomic Ratios & H & $\mathbf{L}$ & LL & $\mathrm{Cl}$ & Sadiya \\
\hline $\mathrm{Mg} / \mathrm{Si}$ & 0.957 & 0.931 & 0.935 & 1.068 & 0.948 \\
\hline $\left.\mathrm{Al} / \mathrm{Si}^{*}{ }^{*} 10^{4}\right)$ & 696 & 686 & 655 & 853 & 826 \\
\hline $\mathrm{Ca} / \mathrm{Si}^{\left(* 10^{4}\right)}$ & 518 & 496 & 482 & 614 & 705 \\
\hline $\mathrm{Fe} / \mathrm{Si}\left({ }^{*} 10^{4}\right)$ & 8184 & 5845 & 4923 & 8717 & 4931 \\
\hline $\mathrm{Ca} / \mathrm{Al}$ & 0.74 & 0.72 & 0.74 & 0.72 & 0.85 \\
\hline $\mathrm{Ni} / \mathrm{Si}\left({ }^{*} 10^{4}\right)$ & 453 & 310 & 258 & 488 & 166 \\
\hline $\begin{array}{l}\text { CI Normalized } \\
\text { Atomic Ratios }\end{array}$ & $\mathbf{H}$ & $\mathbf{L}$ & LL & $\mathbf{C l}$ & Sadiya \\
\hline $\mathrm{Mg} / \mathrm{Si}$ & 0.9 & 0.87 & 0.88 & 1 & 0.889 \\
\hline $\mathrm{Al} / \mathrm{Si}$ & 0.82 & 0.81 & 0.77 & 1 & 0.968 \\
\hline $\mathrm{Fe} / \mathrm{Si}$ & 0.94 & 0.67 & 0.56 & 1 & 0.565 \\
\hline
\end{tabular}

Table 1 Chemical composition and selected atomic ratios of Sadiya meteorite in relation to the composition and characteristic atomic ratios of ordinary chondrites groups and $\mathrm{Cl}$ carbonaceous chondrites [8].

$[6,7]$. The results facilitated determination of the major elemental composition of Sadiya meteorite (Table 1), as well its comparison with the average values for $\mathrm{H}, \mathrm{L}, \mathrm{LL}$ and $\mathrm{CI}$ ordinary chondrites [8]. The range for chemical group in ordinary chondrite is generally expressed as endmember content. According to the definition in Van Schmus and Wood and in Hutchison [8,9], the chemical groups in ordinary chondrites are: $\mathrm{H}\left(\mathrm{Fa}_{16-20}\right.$ and $\left.\mathrm{Fs}_{14-18}\right), \mathrm{L}\left(\mathrm{Fa}_{22-26}\right.$ and $\left.\mathrm{Fs}_{19-22}\right)$, and $\mathrm{LL}$ $\left(\mathrm{Fa}_{27-32}\right.$ and $\left.\mathrm{Fs}_{22-26}\right)$. The olivine and pyroxene composition of Sadiya meteorite are estimated to $\mathrm{Fa}_{28.97} ; \mathrm{Fo}_{71.03} ; \mathrm{Fs}_{24.47} ; \mathrm{En}_{74.03}$ and $\mathrm{Wo}_{1.5}$. These

values are identical to the LL group of ordinary chondrite. Chemical composition and selected atomic ratios of Sadiya meteorite are also represent LL group of ordinary chondrite (Table 1).

However, the Raman spectroscopy has not regularly been used as a method for meteorite chemical classification. This technique has already been used for meteorite characterization, especially Lunar and Martian rocks $[10,11]$. The correlation between composition of olivine and pyroxene has been investigated by many authors [11-14]. Recently, the potential of Raman spectroscopy has been largely exploited for the identification of shock-induced features or shock-induced polymorphs in meteorites and classification of the metamorphic stage in low-grade chondrites by many authors [4,15-17].

The Raman spectra of the sample shows (Figure 3 ) two characteristics peaks of olivine at $819.95 \mathrm{~cm}^{-1}$ (Peak A); $850.20 \mathrm{~cm}^{-1}$ (Peak B) and three characteristic peaks of pyroxene at $335.34 \mathrm{~cm}^{-1}$ (Peak A); $678.49 \mathrm{~cm}^{-1}$ (Peak B) and $1004.50 \mathrm{~cm}^{-1}$ (Peak C) [5,6,18-20]. The endmembers are responsible for these characteristics peak changes [5,6,18-21]. Comparison of chemical group attribution based on theoretical Raman peak position prescribe by Pittarello et al. with the Raman peaks of Sadiya meteorite indicative to LL ordinary chondrite (Table 2) which is consistent to the compositional and mineralogical analysis.

Gyollai et al. indicates that the structural disordering in Si-O stretching vibrational modes and $\mathrm{SiO}_{4}$ tetrahedra rotational vibrations are considerable to the shock-metamorphism [22]. The full width at half maximum (FWHM) of the peak is considered to be related to the degree of structural disorder of the crystal [4]. The FWHM values of Sadiya meteorite can be related to the degree of crystal structural disorder resulting from shock deformation. The measured FWHM averaged for the observed peaks for forsterites in the Sadiya meteorite sample is $10.42 \mathrm{~cm}^{-1}$ for the component at $819.95 \mathrm{~cm}^{-1}$ and $27.28 \mathrm{~cm}^{-1}$ for the component at $850.20 \mathrm{~cm}^{-1}$. The well-crystallized terrestrial olivines have FWHM value $9.1 \mathrm{~cm}^{-1}$ and $9.5 \mathrm{~cm}^{-1}$ corresponding to the peak positions at $820 \mathrm{~cm}^{-1}$ and $854 \mathrm{~cm}^{-1}$. The observed FWHM values of Sadiya meteorite are higher than those observed for well-crystallized terrestrial olivines. According to Miyamoto and Ohsumi [23], the FWHM value $10 \mathrm{~cm}^{-1}$ for poorly shocked to $21 \mathrm{~cm}^{-1}$ for strongly shocked meteorites. The FWHM value of $\sim 10-27 \mathrm{~cm}^{-1}$ in Sadiya meteorite in accordance with the moderate to strongly shocked stage [24]. The 
Citation: Saikia BJ, Parthasarathy G, Borah RR, Borthakur R, Sarmah AJD (2017) Meteorite Fall at Sadiya, India: A Raman Spectroscopic Classification. J Astrophys Aerospace Technol 5: 149. doi:10.4172/2329-6542.1000149

Page 3 of 3
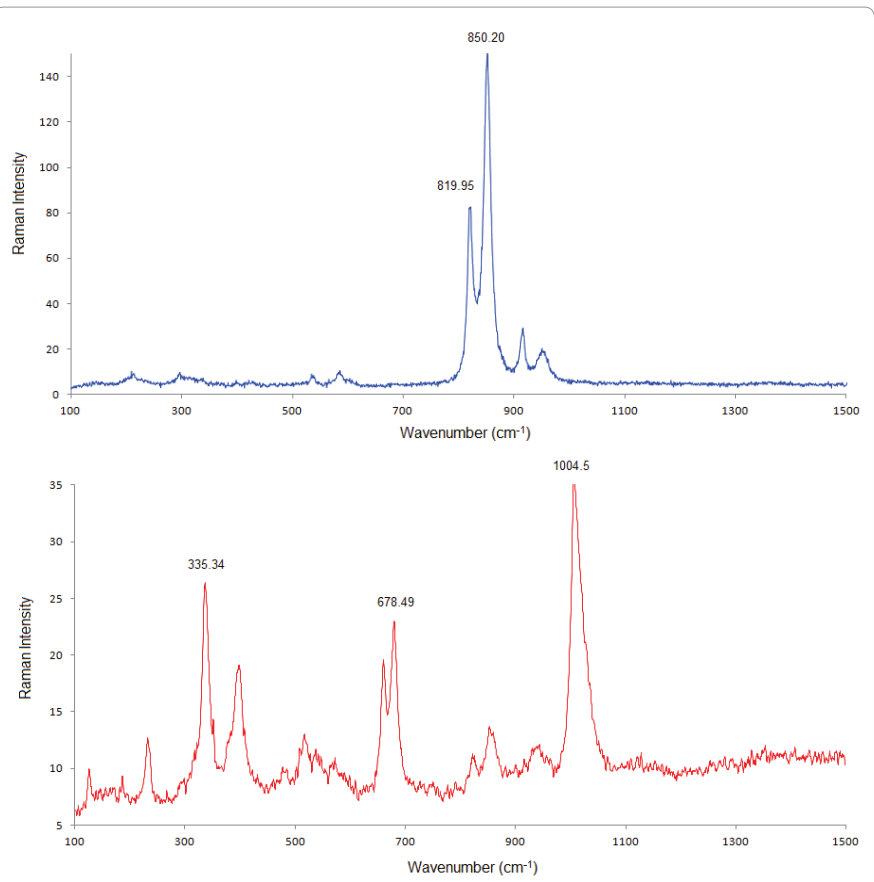

Figure 3: Raman spectra (a) Olivine and (b) Pyroxene of Sadiya meteorite.

\begin{tabular}{|c|c|c|c|c|}
\hline \multicolumn{2}{|c|}{ Chemical Group } & Peak A (cm-1) & Peak B $\left.\mathbf{( c m}^{-1}\right)$ & Peak C (cm-1) \\
\hline \multirow{2}{*}{$\mathrm{H}$} & $\mathrm{Fa}_{16-20}$ & $821.9-822.3$ & $852.5-853.4$ & -- \\
\cline { 2 - 5 } & $\mathrm{Fs}_{14-18}$ & $337.9-339.5$ & $681.2-682.5$ & $1007.8-1009.0$ \\
\hline \multirow{2}{*}{$\mathrm{L}$} & $\mathrm{Fa}_{22-26}$ & $821.3-821.7$ & $851.2-852.1$ & -- \\
\cline { 2 - 5 } & $\mathrm{Fs}_{19-22}$ & $336.5-337.6$ & $679.9-680.8$ & $1006.6-1007.5$ \\
\hline \multirow{2}{*}{$\mathrm{LL}$} & $\mathrm{Fa}_{26-32}$ & $820.6-821.3$ & $849.9-851.2$ & -- \\
\cline { 2 - 5 } & $\mathrm{Fs}_{22-26}$ & $334.9-336.5$ & $678.6-679.9$ & $1005.5-1006.6$ \\
\hline \multirow{2}{*}{ Sadiya } & $\mathrm{Fa}_{28.97}$ & 819.95 & 850.20 & - \\
\cline { 2 - 5 } & $\mathrm{Fs}_{24.47}$ & 335.34 & 678.49 & 1004.50 \\
\hline
\end{tabular}

Table 2 Chemical group attribution based on theoretical Raman peak positions compared with Sadiya meteorite [2]

FWHM value $34.3 \mathrm{~cm}^{-1}$ for the pyroxene peak at $1004.50 \mathrm{~cm}^{-1}$ of Sadiya meteorite is higher than the well-crystallized terrestrial pyroxenes [4].

\section{Conclusion}

The measured Raman band positions and relative intensities are consistent with chemical composition for olivines and pyroxenes and show influence of shock. The Raman spectroscopic results are complementary to SEM-EDX and compositional analysis. Preliminary assessment suggests that the Sadiya meteorite resemble moderate to strongly shocked ordinary chondrites and it may be classified as LL-5 group.

\section{Acknowledgements}

We thank, Director, Indian Institute of Technology, Guwahati (IITG) for analytical facilities; Dr. S. Sarmah, IITG for his assistance with the spectroscopic analysis. We also thank Superintendents of Police, Sadiya for cooperation. G.P. is thankful to CSIR, PLANEX program of PRL, ISRO-Space Application Centre for their support.

\section{References}

1. Nair AGC, Acharya R, Sudarshan K, Gangotra S, Reddy AVR, et al. (2003) Development of an internal mono standard INAA method based on in situ detection efficiency for analysis of large and non-standard geometry samples. Anal Chem 75: 4868-4874.

2. Pittarello L, Baert K, Debaille V, Claeys P (2015) Screening and classification of ordinary chondrites by Raman spectroscopy. Meteorit Planet Sci 50: 17181732.

3. Saikia BJ, Parthasarathy G, Borah RR (2017) Mineralogy of meteorites from the North-eastern India: A brief review. Geometarials 7: 83-95.

4. Rull F, Espadas MJM, Lunar R, Martinez-Frias J (2010) Raman spectroscopic study of four Spanish shocked ordinary chondrites: Cañellas, Olmedilla de Alarcón, Reliegos and Olivenza. Phil Trans R Soc A 368: 3153-3166.

5. Saikia BJ, Parthasarathy G, Sarmah NC (2009) Spectroscopic characterization of olivine $(\mathrm{Fe}, \mathrm{Mg})_{2} \mathrm{SiO}_{4}$ in Mahadevpur $\mathrm{H} 4 / 5$ ordinary chondrite. J Am Sci 5: 71-78.

6. Saikia BJ, Parthasarathy G, Borah RR (2017) Nanodiamonds and silicate minerals in ordinary chondrites as determined by micro-Raman spectroscopy. Meteorit Planet Sci 52: 1146-1154.

7. Bhandari N, Murty SVS, Shukla PN, Mahajan RR, Shukla AD, et al. (2005) Bhawad LL6 chondrite: Chemistry, petrology, noble gases, nuclear tracks and cosmogenic radionuclides. Meteorit Planet Sci 40: 1015-1022.

8. Hutchison R (2006) Meteorites: A petrologic, chemical and isotopic synthesis Cambridge University Press, Cambridge, UK.

9. Van Schmus WR, Wood JA (1967) A chemical- petrologic classification for the chondritic meteorites. Geochim Cosmochim Acta 31: 747-765.

10. Haskin LA, Wang A, Rockow KM, Jolliff BL, Korotev RL et al. (1997) Raman spectroscopy for mineral identification and quantification for in situ planetary surface analysis: A point count method. J Geophys Res 102: 19293-19306.

11. Wang A, Kuebler K, Jolliff B, Haskin LA (2004) Mineralogy of a Martian meteorite as determined by Raman spectroscopy. J Raman Spectros 35: 504-514.

12. Huang $\mathrm{E}$, Chen $\mathrm{CH}$, Huang $\mathrm{T}$, Lin $\mathrm{EH}, \mathrm{Xu} \mathrm{J}$ (2000) Raman spectroscopic characteristics of Mg-Fe-Ca pyroxenes. Am Mineral 85: 473-479.

13. Wang A, Jolliff BL, Haskin LA, Kuebler KE, Viskupic KM (2001) Characterization and comparison of structural and compositional features of planetary quadrilateral pyroxenes by Raman spectroscopy. Am Mineral 86: 790-806.

14. Kuebler KE, Jolliff BL, Wang A, Haskin LA (2006) Extracting olivine (Fo-Fa) compositions from Raman spectral peak positions. Geochim Cosmochim Acta 70: 6201-6222.

15. Wang D, Chen M (2006) Shock-induced melting, recrystallization, and exsolution in plagioclase from the Martian Iherzolitic shergottite GRV 99027. Meteorit Planet Sci 41: 519-527.

16. Gillet P, El Goresy A, Beck P, Chen M (2007) Highpressure mineral assemblages in shocked meteorites and shocked terrestrial rocks: Mechanisms of phase transformations and constraints to pressure and temperature histories. GSA Special Papers 421: 57-82.

17. Quirico E, Montagnac G, Rouzaud JN, Bonal L, Bourot DM, et al. (2009) Precursor and metamorphic condition effects on Raman spectra of poorly ordered carbonaceous matter in chondrites and coals. Earth Planet Sci Lett 287: $185-193$

18. Saikia BJ, Parthasarathy G (2009) Spectroscopic investigation of Mahadevpu H4/5 ordinary chondrite. Geochim Cosmochim Acta 73: 1144

19. Saikia BJ, Parthasarathy G, Borah RR, Borthakur R (2016) Raman spectroscopic study of Dergaon H5 and Mahadevpur H4/5 chondrite. Proceedings of the 47th Lunar and Planetary Science Conference.

20. Saikia BJ, Parthasarathy G, Borah RR (2017) Raman spectroscopy of Kamargaon L6 ordinary chondrite. Proceedings of the 48th Lunar and Planetary Science Conference, The Woodlands, Texas.

21. Saikia BJ, Parthasarathy G, Sarmah NC (2009) Fourier transform infrared spectroscopic characterization of Dergaon H5 chondrite: Evidence of aliphatic organic compound. Nat Sci 7: 45-51.

22. Gyollai I, Nagya S, Fürja J, Bérczia S, Gucsik A, et al (2009) Petrographic and micro-raman study of thermal and shock metamorphism in Mezőmadaras, Knyahinya and Mócs LChondrites in A. Gucsik (Ed.) Micro-raman spectroscopy and luminescence studies in the earth and planetary sciences, American Institute of Physics, USA

23. Miyamoto M, Ohsumi K (1995) Micro Raman spectroscopy of olivines in L6 chondrites: Evaluation of the degree of shock. Geophys Res Lett 22: 437-440.

24. Stoffler D, Keil K, Scott ERD (1991) Shock metamorphism of ordinary chondrites in Geochim Cosmochim Acta 55: 3845-3867. 